\section{ANALYSIS OF BAR FEEDING INTO THE DRAWING TOOL}

JAN RIHACEK, KAMIL PODANY, DAVID KABILKA, LIBOR MRNA

${ }^{1}$ Brno University of Technology, Faculty of Mechanical Engineering, Institute of Manufacturing Technology, Brno,

Czech Republic

DOI : 10.17973/MMSJ.2019_12_2019040

e-mail: rihacek.j@fme.vutbr.cz

The paper deals with a study of buckling behaviour of a bar, which is fed into the drawing tool in the production of drawn bar. When the undrawn bar is inserting into the two-die drawing tool by using hydraulic feeding collets, it can be buckled and stuffed between dies. Accordingly, basic parameters, such as a maximum possible buckling length, have to be found. Due to a specific shape of the drawn bar face, but also due to other parameters, the usage of basic equations for the calculation of buckling stability is questionable. Therefore, the numerical simulation in the ANSYS software was used. Based on basic calculations, numerical simulations and practical experiments, conditions under which the current bar feeding method can be used is found, followed by results comparison.

KEYWORDS

ANSYS, numerical simulation, bar drawing, buckling stability, CK67 steel

\section{INTRODUCTION}

In the area of bulk forming, bars and wires of circular crosssections are most often produced by the drawing tehnology. In this case, the solved issue contains the feeding of the bar with a diameter of $14 \mathrm{~mm}$ into the two-die drawing tool using Schumag draw bench, see Fig. 1. [ASM 1998], [Hosford 2014]

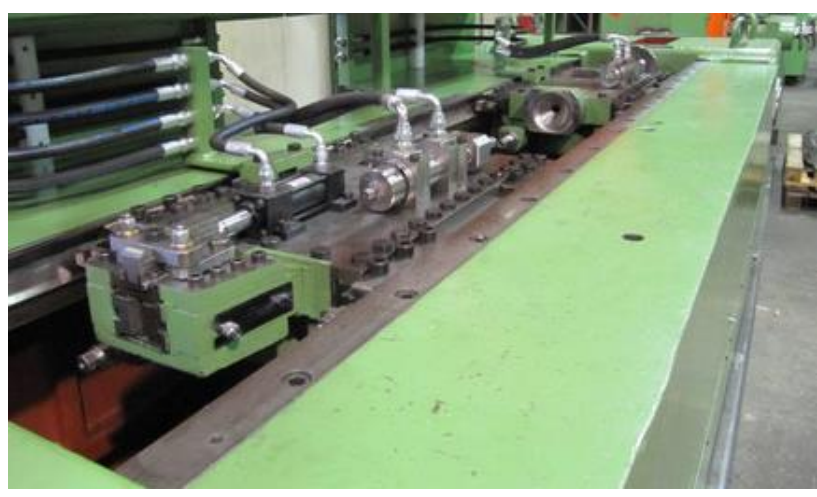

Figure 1. Schumag drawing machine [Kabilka 2019]

The bar is made of CK67 steel. Main mechanical properties and chemical composition of mentioned steel are summarized in Tab. 1 and Tab. 2.

\begin{tabular}{|l|l|l||l|}
\hline Young's modulus & $\mathrm{E}$ & {$[\mathrm{GPa}]$} & 207 \\
\hline Minimal upper yield stress & $\mathrm{R}_{\mathrm{p}} 0.2$ & {$[\mathrm{MPa}]$} & 638.4 \\
\hline Ultimate strength & $\mathrm{R}_{\mathrm{m}}$ & {$[\mathrm{MPa}]$} & 1008.3 \\
\hline Ductility & $\mathrm{A}_{5}$ & {$[\%]$} & 15.3 \\
\hline
\end{tabular}

Table 1. Mechanical properties of CK67 steel

\begin{tabular}{|c|c|c|c|}
\hline$\% \mathrm{C}$ & \multicolumn{2}{|c|}{$\% \mathrm{Si}$} & $\% \mathrm{Mn}$ \\
\hline $0.65-0.70$ & \multicolumn{2}{|c|}{$0.15-0.30$} & $0.65-0.80$ \\
\hline$\% P$ & $\% \mathrm{~S}$ & $\% \mathrm{Cr}$ & $\% \mathrm{Al}$ \\
\hline $\max .0 .015$ & $\max .0 .015$ & $0.15-0.30$ & $\max .0 .04$ \\
\hline
\end{tabular}

The entire manufacturing process consists of several stages. The bar goes through these main operations:

1. straightening before drawing,

2. surface blasting (dirt removal),

3. Iubrication,

4. own bar drawing using two drawing dies,

5. straightening after drawing

6. quality control using eddy currents,

7. cutting of the drawn bar,

8. polishing.

In order to feed it through the drawing machine successfully, the face of the bar should be modified using a pointing machine. However, the use of the mentioned device entails the need to adjust the production line and also economic difficulties. Therefore, feeding of the bar without the use of the pointing machine was selected. The face of the bar is thus only cut off, as it is shown in Fig. 2. [ASM 1998]

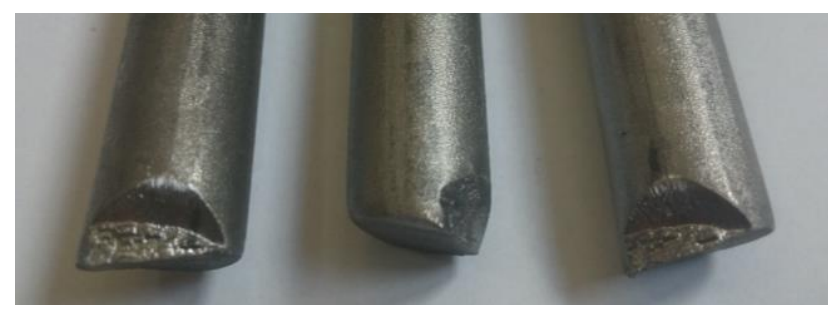

Figure 2. Faces of bars after cutting

During the drawing operation, the bar diameter is firstly reduced to $13.77 \mathrm{~mm}$. In the second die, it is diminished to a final value of $12.88 \mathrm{~mm}$. The use of two-die drawing process improves the quality of the drawn bar. However, the disadvantage of the twodie drawing process is a problem with loosing of buckling stability at the beginning of the production, when the undrawn bar is fed into dies, unlike one-die drawing system. An Umformoel $80 \mathrm{M}$ lubricant is used to improve the drawing process. A detail of the hydraulic feeding collets, including its feeding length limitation is shown in Fig. 3. Shapes of dies, which are made of cemented carbide, for the first and second stage comply with the ČSN EN standard. Unfortunately, it is not possible to publish an exact shape and dimensions of drawing tools due to the confidentiality.

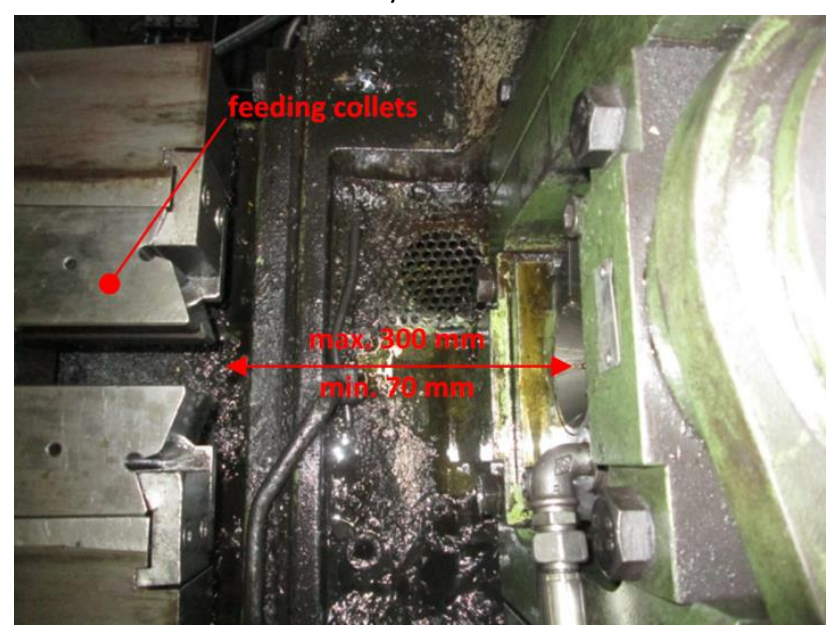

Figure 3. Length limitation during bar inserting into the drawing die

As it was mentioned above, the main solved problem is the loss of buckling stability of the fed bar. This problem is illustrated in Fig. 4, which shows a jammed drawn bar after loss of its buckling stability.

Table 2. Chemical composition of CK67 steel 


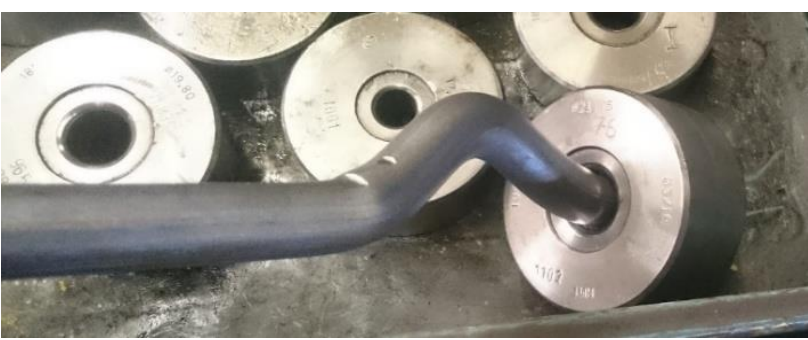

Figure 4. Jammed bar [Kabilka 2019]

\section{PRACTICAL EVALUATION OF DRAWING PROCESS}

In order to obtain and evaluate the basic parameters of the bar drawing process, an experimental drawing device has been designed and manufactured, see Fig. 5. The main part of the device is a case, into which distance rings and dies are inserted. For this case, distance rings with a total height of $10 \mathrm{~mm}$ were used. The case is closed with a cover at the top. Moreover, a centering element is inserted in the cover, into which a guide sleeve is placed. Accordingly, the drawn bar is moved over the guide sleeve towards the first die and it is guided from the top by upper guide element. The role of the guide sleeve is to center the bar so that it is pushed into the first die in the ideal direction with minimal radial deviation. This is because the experimental device does not allow the use of collets. It just pushes on the upper guide element. Therefore, there is an effort to center the bar during the initial feeding phase, i.e. feeding into the first die. After that, the feeding process is interrupted, the guide sleeve is removed and the experimental simulation of the feeding process continues without it. Since the problem occurs only when the bar is in the second die, this solution should not affect the results of the experiment.
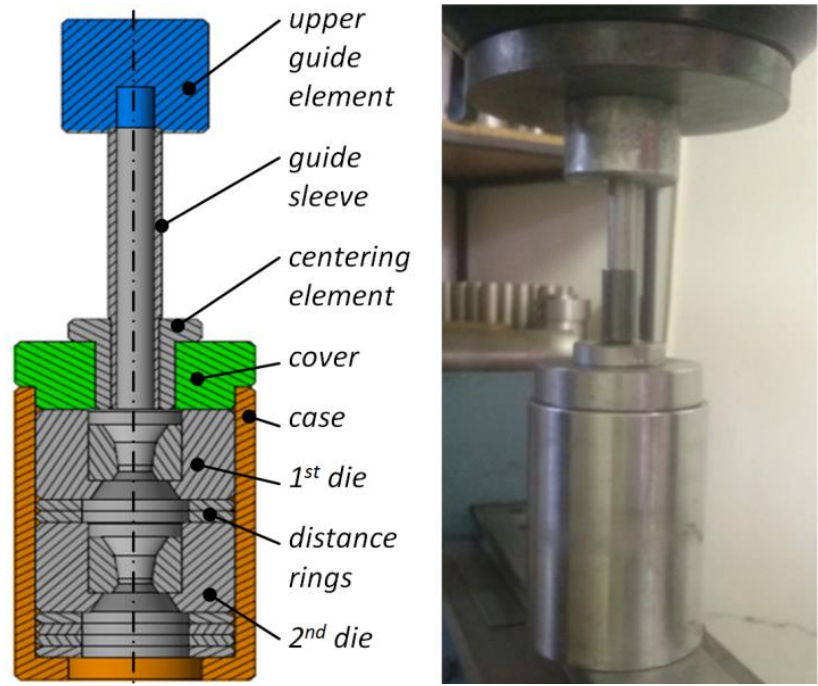

a) schematic view

b) practical realization

Figure 5. Experimental drawing device [Kabilka 2019]

From the point of view of tests repeatability, it was always necessary to push the drawn bar out from dies to feed the next specimen. For this purpose, a hardened bar with diameter of $12.5 \mathrm{~mm}$ was used. The whole device was tested in conjunction with ZD 40 universal testing machine. An evaluation of recorded values was performed by using M-TEST software. The graph in Fig. 6 shows detected load curves. It is the dependence of the feeding force on the stroke including a force decrease when the guide sleeve is removed. It is an average of three measurements. In this case, the bar with length of $120 \mathrm{~mm}$ was tested to ensure that the bar did not lose buckling stability.

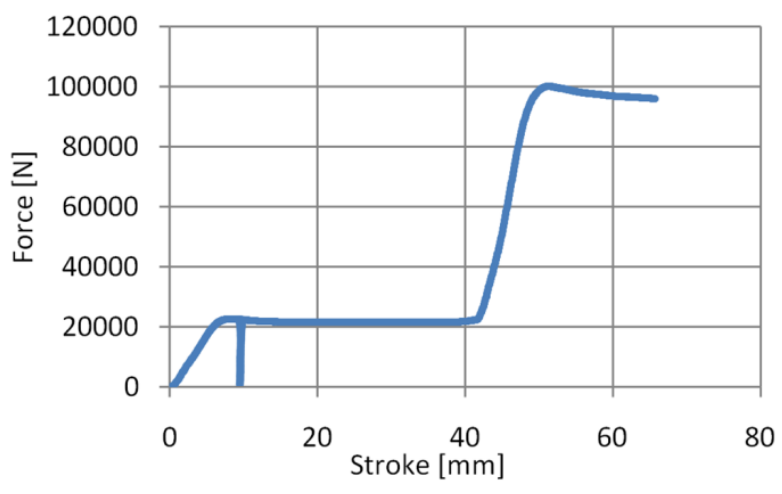

Figure 6. Feeding force - tool stroke graph (feeding at once)

As it is obvious from the graph, the feeding process was conducted nearly continuously. Nevertheless, the feeding process is intermittent in the real process. After each stroke, feeding collets return to the start position and then feed again along the same path until the bar is fully fed into the tool. Therefore, the experiment was performed under different conditions, which correspond more closely to reality, i.e. with repeated interruption of the feeding process, see Fig. 6 .

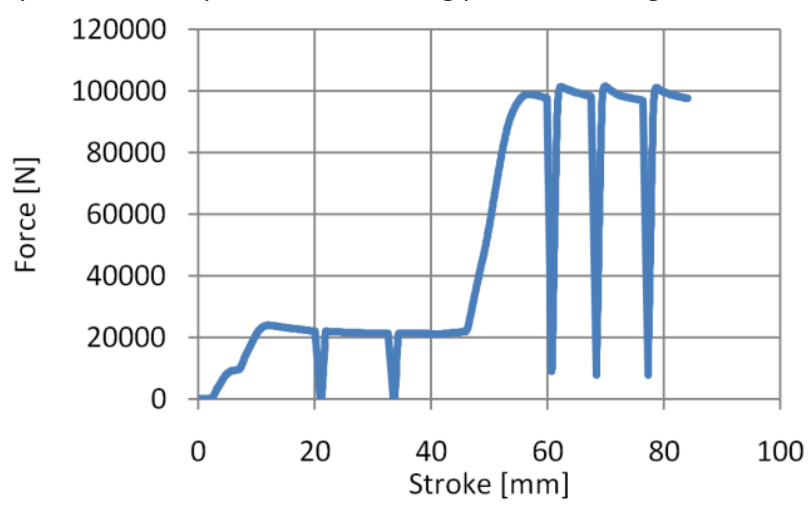

Figure 7. Feeding force - tool stroke graph (intermittent feeding)

If the above graphs are compared, it is obvious that the interruption of the feeding operation causes an increase in the necessary feeding force, namely for the second die. In both cases, a force of approximately $23.5 \mathrm{kN}$ is required for bar feeding into the first die (stroke of approx. $10 \mathrm{~mm}$ ). In the second die (stroke of approx. $50 \mathrm{~mm}$ ), a slight increase in the feeding force can be already observed, during the intermittent feeding. In this case, the force is increased from $100 \mathrm{kN}$ to $102 \mathrm{kN}$. Anyway, values of the required feeding force can be used for further calculations, namely for buckling stability.

\section{BUCKLING STABILITY CALCULATION}

Various methods can be used to solve buckling stability problems. Since the path of the feeding collets is in the range of 300 to $70 \mathrm{~mm}$, it is necessary to determine the appropriate free length of the bar so as to avoid buckling stability. In this case, well-known basic schemes can be used firstly, according to Fig. 8 .

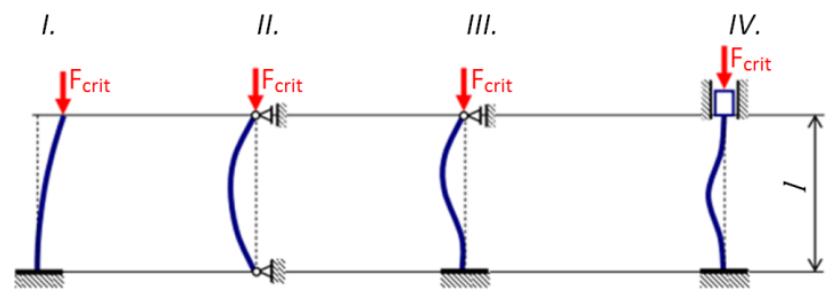

Figure 8. Basic schemes of buckling constraint types [Chakrabarti 2005], [Kabilka 2019] 
A basic relationship for critical force at which loss of stability occurs is possible to use for the theoretical calculation of the maximum bar length according to Euler's equation:

$F_{\text {crit }}=n \cdot \frac{\pi^{2} \cdot \mathrm{E} \cdot \mathrm{J}}{l^{2}}=n \cdot \frac{\pi^{2} \cdot \mathrm{E} \cdot \mathrm{D}^{4}}{64 \cdot l^{2}} \rightarrow l=\sqrt{n \cdot \frac{\pi^{2} \cdot \mathrm{E} \cdot \mathrm{D}^{4}}{64 \cdot F_{\text {crit }}}}$

where $F_{\text {crit }}$ is the critical buckling force $[N]$, I is the critical buckling length [mm], $\mathrm{n}$ is the buckling coefficient for actual constraint type [-], $\mathrm{E}$ is the Young's modulus [MPa], $\mathrm{J}$ is the quadratic moment of cross-section $\left[\mathrm{mm}^{4}\right]$ and $D$ is the undrawn bar diameter. [Kabilka 2019], [Lindeburg 2014]

In some cases, the modified form of the above mentioned equation is also used:

$F_{\text {crit }}=\frac{\pi^{2} \cdot E \cdot J}{l_{\text {eff }}{ }^{2}}=\frac{\pi^{2} \cdot E \cdot J}{(k \cdot l)^{2}}=\frac{\pi^{2} \cdot E \cdot J}{\left(\sqrt{\frac{1}{n}} \cdot l\right)^{2}}$

where $l_{\text {eff }}$ is the effective buckling length $[\mathrm{mm}]$ and $\mathrm{k}$ is the effective length factor [-]. [Chakrabarti 2005], [Lindeburg 2014]

For above mentioned constraint types, values of $n$ and $k$ are tabulated in Tab. 3. In addition to theoretical values, there are also recommended values for practical design of structural members. It is important to note that some recommended coefficients differ across literature sources. For constraint type IV., there is the variance of recommended $\mathrm{k}$ value between 0.6 and 0.9. In this case, $k$ value of 0.9 was used, which corresponds to $\mathrm{n}$ value of 1.23. [Lindeburg 2014]

\begin{tabular}{|l|l||c|c|c|c|}
\hline \multicolumn{2}{|l||}{ Constraint type } & I. & II. & III. & IV. \\
\hline \hline \multirow{2}{*}{\begin{tabular}{l} 
values \\
\cline { 2 - 6 } k values
\end{tabular}} & theoretical & 0.25 & 1.00 & 2.04 & 4.00 \\
\cline { 2 - 6 } & recommended & 0.23 & 1.00 & 1.56 & 1.23 \\
\cline { 2 - 6 } & theoretical & 2.00 & 1.00 & 0.70 & 0.50 \\
\hline
\end{tabular}

Table 3. Constraint type effect on buckling coefficients [Chakrabarti 2005], [Lindeburg 2014]

If the undrawn bar diameter of $14 \mathrm{~mm}$ and Young's modulus of $207 \mathrm{GPa}$ are considered, the values in Tab. 4 and Tab. 5 can be calculated according to equation 1.

\begin{tabular}{|l|l|l|}
\hline \multirow{2}{*}{ Constraint type } & \multicolumn{2}{|c|}{ Critical buckling length [mm] } \\
\cline { 2 - 3 } & $\begin{array}{l}\text { for theoretical } \\
\text { n values }\end{array}$ & $\begin{array}{l}\text { for recommended } \\
\text { design } \mathrm{n} \text { values }\end{array}$ \\
\hline \hline I. & 114.22 & 109.55 \\
\hline II. & 228.44 & 228.44 \\
\hline III. & 326.27 & 285.32 \\
\hline IV. & 456.87 & 253.35 \\
\hline
\end{tabular}

Table 4. Critical buckling lengths for $F_{\text {crit }}=23.5 \mathrm{kN}$

\begin{tabular}{|l|l|l|}
\hline \multirow{2}{*}{ Constraint type } & \multicolumn{2}{|c|}{ Critical buckling length [mm] } \\
\cline { 2 - 3 } & $\begin{array}{l}\text { for theoretical } \\
\text { n values }\end{array}$ & $\begin{array}{l}\text { for recommended } \\
\text { design } \mathrm{n} \text { values }\end{array}$ \\
\hline \hline I. & 54.82 & 52.58 \\
\hline II. & 109.65 & 109.65 \\
\hline III. & 156.61 & 136.95 \\
\hline IV. & 219.30 & 121.60 \\
\hline
\end{tabular}

Table 5. Critical buckling lengths for $F_{\text {crit }}=102 \mathrm{kN}$

It is impotrant to note, that the calculation according to particular constraint types in Fig. 8 gives a relatively large scatter of critical buckling length values, as it is evident from Tab. 4 and Tab. 5. Therefore, it is appropriate to supplement these results with a numerical simulation and experimental verification.

\section{NUMERICAL SIMULATON}

For this purpose, the numerical simulation using FEM in ANSYS Workbench software was used. Firstly, a material model was determined. Due to the prevailing pressure loading, an upsetting test was performed for 5 specimens. The specimens were taken from the rod after straightening process before drawing. Fig. 9 shows the final evaluated flow stress plot.

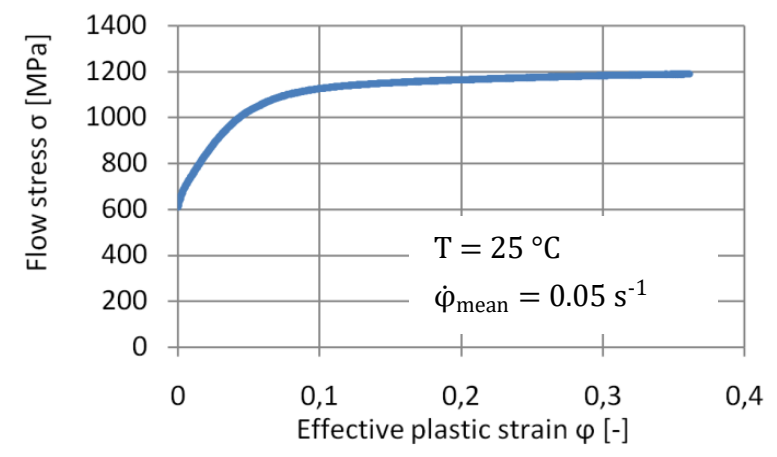

Figure 9. Flow stress of CK 67 steel

The geometry of the bar end was determined by 3D scanning process and then partially modelled in CAD. All tools were considered as ideally rigid. In the next, the Coulomb's coefficient of friction was considered as 0.07 . The whole geometric model is shown in Fig. 10. Hexaedral elements with nominal edge length of $1.5 \mathrm{~mm}$ were used. [Lee 2015], [Valberg 2010]

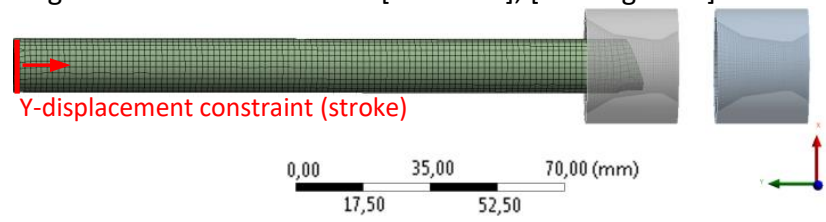

Figure 10. Geometrical model

After the calculation of the drawing process, it is possible to focus on simulation results in post-processing. Firstly, $120 \mathrm{~mm}$ long bar feeding was simulated to verify the simulation accuracy by comparing with experimental data. A distribution of effective plastic strain on the drawn bar is shown in Fig. 11.

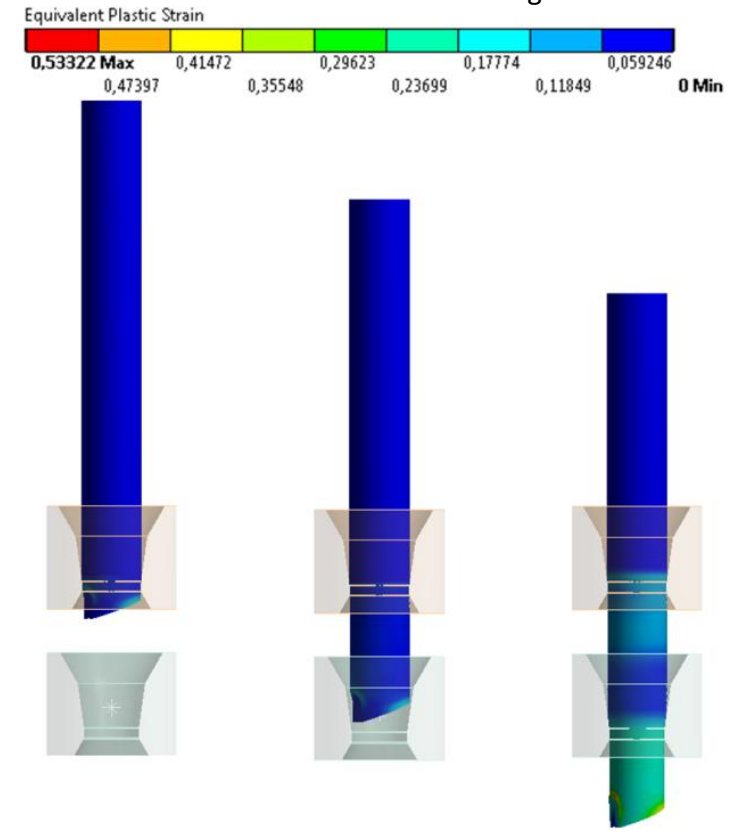

$\begin{array}{lll}\text { a) } 15 \mathrm{~mm} \text { stroke } & \text { b) } 35 \mathrm{~mm} \text { stroke } & \text { c) } 55 \mathrm{~mm} \text { stroke }\end{array}$ Figure 11. Predicted effective plastic strain by using FEM simulation

Fig. 12 shows the comparison between numerical simulation and real feeding process in force-stroke graph. As it is evident from 
this graph, maximum deviation between the simulation and the real process is about $7 \%$. It follows that the numerical simulation gives technically acceptable data and it can be used for further analysis.

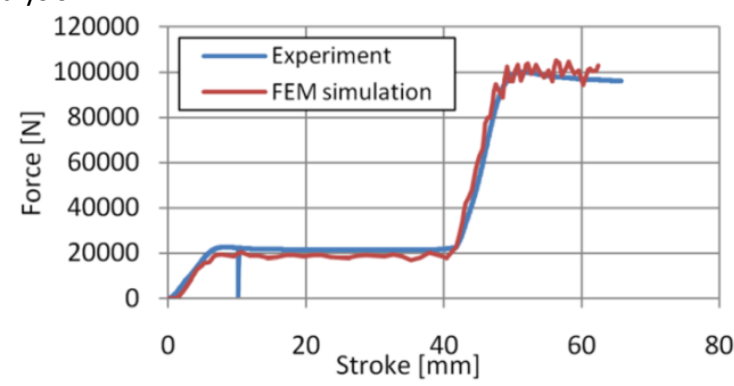

Figure 12. Comparison of feeding forces

Furthermore, the numerical simulation was focused on determination of the limit state of buckling stability. The FEM analysis shows that the problem of buckling stability occurs at the bar length of $162 \mathrm{~mm}$ and at a stroke of $35.4 \mathrm{~mm}$. In this case a lateral deflection of drawn bar begins to take non-zero value, as it is shown in the graph in Fig. 13.

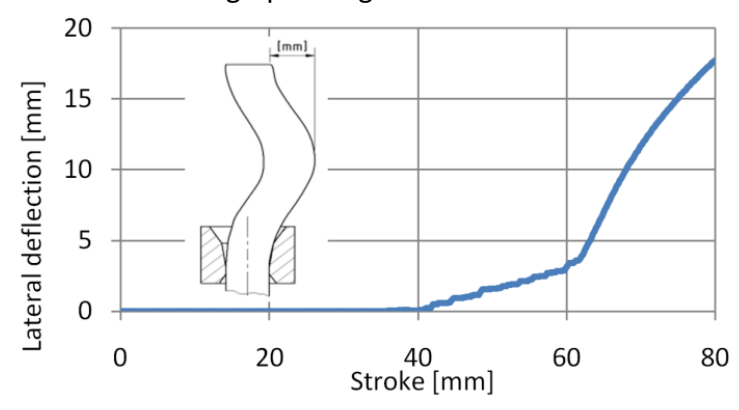

Figure 13. Buckling of $162 \mathrm{~mm}$ length drawn bar

The mentioned overall length and stroke indicate that the loss of stability occurs at a free bar length of $126.6 \mathrm{~mm}$. Predicted effective plastic strain distribution on the drawn bar for overall bar length of $162 \mathrm{~mm}$ is shown in Fig. 14, where the loss of buckling stability is clearly evident.

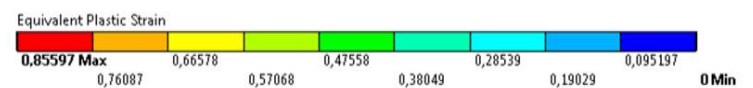

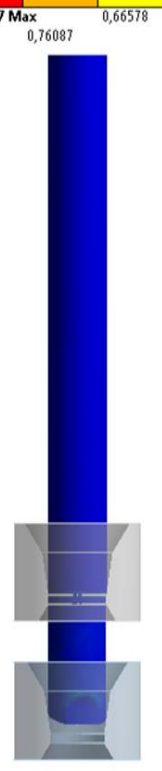

a) $35 \mathrm{~mm}$ stroke

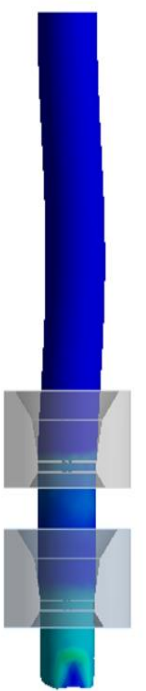

b) $55 \mathrm{~mm}$ stroke

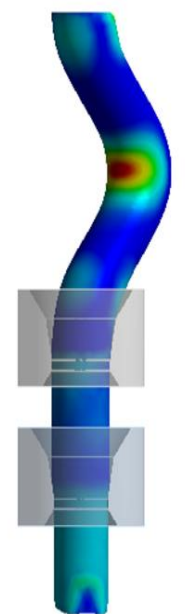

c) $75 \mathrm{~mm}$ stroke
Figure 14. Predicted effective plastic strain by using FEM simulation

\section{EXPERIMENTAL VERIFICATION}

The loss of buckling stability and the critical length were also sought using the experimental solution. Using the experimental drawing device, a number of bar specimen lengths were investigated. Experiments show that the buckling stability problem occurs at a stroke of $36.4 \mathrm{~mm}$ for an initial rod length of $155 \mathrm{~mm}$, which corresponds to the free bar length of $118.6 \mathrm{~mm}$. Fig. 15 shows a comparison of feeding force curves for mentioned initial length and also for $150 \mathrm{~mm}$. The graph shows the deviation (decrease) of the feeding force at the point of loss of buckling stability, namely at a stroke of $36.4 \mathrm{~mm}$. In this case, the initial length is the distance from the fed face of the bar to the front face of the upper guide element.

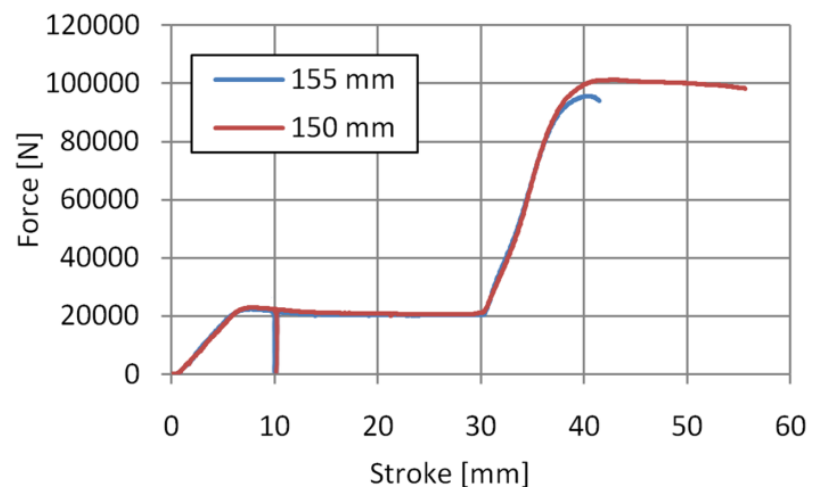

Figure 15. Comparison of feeding forces for different bar lengths

Compared to the results of the numerical simulation, the determined critical buckling length of $118.6 \mathrm{~mm}$ is about $6.7 \%$ smaller. It is important to note that the comparison should in any case be taken with some margin, because the FEM simulation neglects the effect of drawn bars slight deflections, which even the straightening operation before drawing cannot completely eliminate in practice.

Simultaneously, it is possible to compare the simulation and experiment results with theoretical calculations. It obvious, that the constraint type IV (fixed-fixed), which predicts the critical length value of $121.6 \mathrm{~mm}$, is the closest to the real value (118.6 $\mathrm{mm}$ ). However, it should be noted that the experimentally determined values might be quite different depending on the selected buckling coefficient. In the case of the constraint type IV, the critical length value can thus vary from $121.6 \mathrm{~mm}$ to 219.3 $\mathrm{mm}$, i.e. for $\mathrm{n}$ value from 1.23 to 4 .

\section{CONCLUSIONS}

Based on the problem with bar feeding into the two-die drawing tool by using hydraulic feeding collets, the analysis of the feeding process and buckling stability evaluation was performed. The aim was to feed the bar into the drawing tool without the use of the pointing machine. For this purpose, the experimental drawing device was designed and manufactured to verify the possibilities of bar feeding.

Furthermore, the maximum allowable free length of the fed bar was determined on the basis of three approaches. This mainly involved the use of FEM numerical simulation in ANSYS software. FEM results were then compared with theoretical solutions based on well-known equations and the experimental verification. The comparison showed a good agreement between the simulation, theoretical calculation for the constraint type IV and performed experiments. At the same time, it should be noted that results obtained on the basis of the theoretical calculation for mentioned constraint type show a large dispersion based on the chosen buckling coefficient. 


\section{REFERENCES}

[ASM 1998] ASM Internacional. ASM Handbook Volume 14: Forming and Gorging. Materials Park, $\mathrm{OH}$ : ASM International, 1998. ISBN 978-0871700209

[Hosford 2014] Hosford, W. F. and Caddel, R. M. Metal Forming: Mechanics and Metallurgy. Cambridge: Cambridge University Press, 2014. ISBN 978-1-107-00452-8

[Chakrabarti 2005] Chakrabarti, Subrata. Handbook of Offshore Engineering. Elsevier Science, 2005. ISBN 978-0-08-044381-2.

[Kabilka 2019] Kabilka, D. Optimization of the Wire Drawing Process. Brno: Brno University of Technology, 2019.

[Lee 2015] Lee, H.H. Finite Element Simulations with ANSYS

Workbench 16: Theory, Applications, Case Studies. Kansas: SDC, ISBN 978-1-585-03983-8

[Lindeburg 2014] Lindeburg, Michael R. Civil engineering reference manual for the PE Exam. Belmont, California: Professional Publications, 2014. ISBN 1591264537.

[Valberg 2010] Valberg, H. S. Applied Metal Forming including FEM Analysis. Trondheim: Norwegian University of Science and Technology, 2010. ISBN 978-05-21518-23-9.

\section{CONTACTS:}

Ing. Jan Rihacek, Ph.D.; Ing. Kamil Podany, Ph.D.; Ing. David Kabilka; doc. RNDr. Libor Mrna, Ph.D.

Brno University of Technology, Faculty of Mechanical Engineering, Institute of Manufacturing Technology Technická 2896/2, Brno, 616 69, Czech Republic e-mail: rihacek.j@fme.vutbr.cz 